\title{
Purification, biochemical characterization and self-assembled structure of a fengycin-like antifungal peptide from Bacillus thuringiensis strain SM1
}

\author{
Anupam Roy ${ }^{1}$, Denial Mahata ${ }^{1}$, Debarati Paul ${ }^{2}$, Suresh Korpole ${ }^{3}$, Octavio L. Franco ${ }^{4}$ and \\ Santi M. Mandal ${ }^{1}$ * \\ 1 Central Research Facility, Indian Institute of Technology Kharagpur, Kharagpur, India \\ ${ }^{2}$ Amity Institute of Biotechnology, Amity University, Sector 125, Noida, India \\ ${ }^{3}$ Council of Scientific and Industrial Research, Institute of Microbial Technology, Sector 39A, Chandigarh, India \\ ${ }^{4}$ Centro de Análises Proteômicas e Bioquímicas, Pós-Graduação em Ciências Genômicas e Biotecnologia UCB, Brasília, Brazil
}

\section{Edited by:}

Nádia Skorupa Parachin, Universidade de Brasilia-UnB, Brazil

\section{Reviewed by:}

Ilka Maria Vasconcelos, Federal

University of Ceara, Brazil

Jlanxu Li, Emory University, USA

${ }^{*}$ Correspondence:

Santi M. Mandal, Central Research Facility, Indian Institute of Technology Kharagpur, Kharagpur 721302, India e-mail:mandalsm@gmail.com
An antifungal lipopeptide fengycin, producing strain SM1 was isolated from farm land soil sample and identified as Bacillus thuringiensis strain SM1 by using 16S rDNA analysis. Fengycin detected in the culture extract was further purified using HPLC and showed a molecular mass of 1492.8 Da by MALDI-TOF-MS analysis. Purified fengycin was allowed to construct their self-assembled structure onto a hydrophobic surface showing a clear improvement of antibacterial activity. In self-assembly, fengycin adapts a spherical micelle core shell like structure. Self-assembled fengycin may be a successful antimicrobial compound modifying its action from confined antifungal function. Besides it can open up a new area of research in supramolecular lipopeptide based compound making. This can revealed the mode of action of this unique self-assembled structure to fully evaluate its potential for use as an antimicrobial drug to control the emergence of bacterial infection.

Keywords: antimicrobial activity, Bacillus thuringiensis, fengycin, self-assembled structure

\section{INTRODUCTION}

The increasing tendency of microbial infections, rapid emergence of drug-resistant to recent antibiotics and quick evolution through mutation are of great threats to control of microbial infection (Samanta et al., 2013). Infectious disease has become the biggest killer among children and young adults, and has now become a burden to global economics and public health (Jones et al., 2008). This situation is becoming uncontrollable due to unique gained properties of genetically altered pathogens assigned with their unusual clinical symptoms (Gilsdorf and Zilinskas, 2005). Impediment in usual diagnostic and clinical evaluations or preventive strategies forces the modern research to overcome this fatal situation. Research strategies like applying of naturally occurring antimicrobial peptides (AMPs), combined administration of antibiotic agents (Anantharaman et al., 2010), and structural modification of antibiotics are extensively studied (Roy et al., 2013). Furthermore, structural modification of AMPs by self-assembly mechanism is reported to enhance the spectrum of the AMPs (Fernandez-Lopez et al., 2001).

Fengycin, a cyclic lipodecapeptide produced by Bacillus subtilis strain, containing a $\beta$-hydroxy fatty acid with a side-chain length of 16-19 carbon atoms offers an efficient antifungal activity. Like most the natural AMPs, fengycin seems to acts by improving the plasma membrane permeability of the target cell (Vanittanakom et al., 1986). This AMP is known to exhibit strong fungitoxic activity specifically against filamentous fungi, inhibiting enzymes phospholipase A2 and aromatase (Loeffler et al., 1986; Steller and Vater, 2000). Otherwise this peptide also cause hemolytic activity 40 -fold lower than that of surfactin, showing a clear disadvantage
(Hbid, 1996; Schneider et al., 1999; Hathout et al., 2000). In this study, an antifungal peptide fengycin was purified from an $B$. thuringiensis strain SM1 soil isolate. This lipopeptide has been characterized and checked for its antifungal activity against Candida albicans. Additionally, self-aggregation and arrangement of the fengycin molecule were also studied to check whether interfacial modification can enhance the spectrum of the microbial action or not.

\section{MATERIAL AND METHODS IDENTIFICATION OF THE STRAIN}

One gram of farm land soil sample, collected from agricultural farm of IIT-Kharagpur campus, India, was suspended in $9 \mathrm{ml}$ of sterile distilled water. Then $100 \mu \mathrm{l}$ of this was serially diluted and amplified on sterilized LB agar plates with the following composition (g/l): peptic digest of animal tissue, 5.0; beef extract, 1.5; yeast extract, 1.5; sodium chloride, 5.0; agar 15.0 ( $\mathrm{pH}$ adjusted to 7.2). Colonies with inhibition zone in their surroundings were selected for study and streaked on to fresh nutrient agar (NA, HiMedia, India) medium plates. Upon testing their purity all isolates were preserved at $-70^{\circ} \mathrm{C}$ in culture medium containing $50 \%(\mathrm{v} / \mathrm{v})$ glycerol until further use. The tested strain SM1 was grown on tryptone soya agar (TSA) medium. Phenotypic properties including morphology, physiology and biochemical characteristics of the isolate were done using standard procedures (Baindara et al., 2013). The identity of strain SM1 was also confirmed by using 16S rRNA gene sequence (Korpole et al., 2006) blast search analysis. CLUSTAL-W program of MEGA version 5 was used to align the all 16S rRNA gene sequences of the nearest type strains (Tamura et al., 2011) 
downloaded from the NCBI database. Manual correction of alignment was done using BioEdit sequence alignment editor (Hall, 1999). Pair-wise evolutionary distances were calculated with the Kimura two-parameter (Kimura, 1980) and a neighbor-joining phylogenetic tree was constructed using the MEGA version 5.0. 1000 replicates were taken to find the stability of phylogenetic tree.

\section{EXTRACTION OF LIPOPEPTIDE}

A combination of acid and solvent extraction procedure (Vater et al., 2002) was followed to isolate lipopeptide produced from the strain. Centrifugation $(13,000 \times g)$ for $15 \mathrm{~min}$ of the culture broth at $4^{\circ} \mathrm{C}$ resulted cells to pellet down. $\mathrm{pH}$ of the supernatant was adjusted to 2.0 by addition of concentrated $\mathrm{HCl}$. Supernatant of $\mathrm{pH} 2$ was allowed to stand at $4^{\circ} \mathrm{C}$ for $16 \mathrm{~h}$ and resulted in precipitation. The sample was then centrifuged $(13,000 \times g)$ for $20 \mathrm{~min}$ at $4^{\circ} \mathrm{C}$. Precipitate was collected and further extracted with methanol by stirring for $2 \mathrm{~h}$. The lipopeptide containing methanol was collected after filtration and vacuumdried.

\section{PURIFICATION OF LIPOPEPTIDES}

Purification of lipopeptides was carried out as mentioned in Mandal etal. (2013). Extracted lipopeptides was dissolved in methanol. Then we fractionate it by reverse phase- HPLC (Agilent 1100 series, CA, USA) with a ZORBAX 300-SB18 column $(4.6 \mathrm{~mm} \times 250 \mathrm{~mm}$, particle size $5 \mu \mathrm{m})$, at a flow rate of $1 \mathrm{ml} / \mathrm{min}$. The mobile phase components were (A) $0.1 \%$ TFA in water and (B) $0.1 \%$ TFA in $70 \%$ acetonitrile solution. The gradient of solvent $\mathrm{B}$ was used to run the column were : 0 $60 \%$ for $0-45 \mathrm{~min}, 60-80 \%$ for $45-55 \mathrm{~min}$ and $80-100 \%$ for 55-60 min. Eluted peptide from the column were monitored at $215 \mathrm{~nm}$ in a diode array detector. Fractions according to peaks obtained during HPLC were collected using a fraction collector (GILSON, France) coupled with the system. Speed vacuum concentration was used to concentrate the sample and it was then tested for antimicrobial activity. The fractions or peaks that showed antibacterial activity were re-chromatographed in the same column under similar conditions, except solvent B was used as $100 \%$ acetonitrile with a gradient of $0-10 \%$ for $30 \mathrm{~min}$. The peptide concentration was determined using the RP-HPLC conditions and calibrated with surfactin (Sigma-Aldrich, St. Louis, USA).

\section{MALDI-TOF-MS AND SEQUENCING}

Molecular mass and MS/MS sequencing of the purified and active lipopeptides were performed using a Voyager time-of-flight mass spectrometer (Applied Biosystems, CA, USA). Peptides were incubated with $10 \% \mathrm{NaOH}$ in methanol at room temperature for $16 \mathrm{~h}$. Lactone ring present in lipopeptide in MS/MS sequencing was cleaved. Cleaved peptide was liophilizated and extracted with methanol, and allowed it for mass spectrometry analysis. Spectra were recorded in the post-source decay (PSD) ion mode as an average of 100 laser shots with a grid voltage of $75 \%$. The reflector voltage was reduced in $25 \%$ steps and guide wire was reduced $0.02-0.01 \%$ with an extraction delay time of 100 ns.

\section{FATTY ACID ANALYSIS BY GC-MS}

Fatty acid content associated with the lipopeptides was assessed by incubating the peptides ( $5 \mathrm{mg}$ of each) with $0.5 \mathrm{ml}$ of $6 \mathrm{M} \mathrm{HCl}$ at $90^{\circ} \mathrm{C}$ for $18 \mathrm{~h}$ in sealed tubes for acid hydrolysis. Fatty acids were then extracted with ether and treated with $0.95 \mathrm{ml}$ methanol and $0.05 \mathrm{ml}$ of $98 \% \mathrm{H}_{2} \mathrm{SO}_{4}$ at $65^{\circ} \mathrm{C}$ for $6 \mathrm{~h}$. n-hexane extraction was then done to obtain fatty acid methyl esters. Then we analyzed it on GC-MS with a Clarus 500 GC (PerkinElmer, USA) using helium as carrier gas with a flow rate of $1.0 \mathrm{ml} / \mathrm{min}$. The column temperature was then maintained at $120^{\circ} \mathrm{C}$ for $3 \mathrm{~min}$ and thereafter gradually increased $\left(8^{\circ} \mathrm{C} / \mathrm{min}\right)$ to $260^{\circ} \mathrm{C}$.

\section{STRATEGY TO FORM SELF-ASSEMBLED FENGYCIN}

Chloroform solution of fengycin molecule was prepared at a concentration of $0.1 \mathrm{mg} \mathrm{ml}^{-1}$ at neutral $\mathrm{pH}$. The solution was then rotated in chloroform solution for $12 \mathrm{~h}$. and further characterized.

\section{CIRCULAR DICHROISM AND FOURIER TRANSFORM INFRARED SPECTROSCOPY}

Circular dichroism (CD) spectra were recorded using samples at $1 \%$ wt and $\mathrm{pH} 7$ with a path length of $0.001 \mathrm{~cm}$. Spectra were recorded at room temperature from 250 to $180 \mathrm{~nm}$, with a $0.2 \mathrm{~nm}$ data pitch and a scan rate of $50 \mathrm{~nm} \mathrm{~min}^{-1}$ by Jasco810 spectropolarimeter. Millidegrees of rotation were converted to molar residual ellipticity (MRE). For FTIR measurements, both the extract and the reduced colloidal solution were analyzed on a Perkin Elmer FTIR instrument in the diffused reflectance mode at a resolution of $4.0 \mathrm{~cm}^{-1}$.

\section{SCANNING ELECTRON MICROSCOPY}

Aliquots $(100 \mu \mathrm{L})$ of each gel were prepared and placed in a 24 well plate. Overnight chloroform rotated samples were then affixed to SEM pucks using conductive carbon tape. The pucks were sputtercoated with gold using a CRC-150 sputter coater and imaged using an FEI Quanta 400 ESEM at $20.00 \mathrm{kV}$.

\section{ANTIMICROBIAL ASSAYS AND MIC DETERMINATION}

Minimum inhibitory concentration (MIC) values of fengycin for antifungal or antibacterial activities were determined as followed by Samanta et al. (2013). The bacterial strains Staphylococcus epidermidis NCIM 2493 and gram negative Escherichia coli, fungal strains C. albicans and Aspergillus niger were taken in the study. These strains were cultured according to their specifications. Both, fenzycin and self-assembled fengycin was used at a concentration range from $1 \mathrm{mg} \mathrm{ml}^{-1}$ to $1.95 \mu \mathrm{g} \mathrm{ml}^{-1}$ to evaluate the antifungal and antimicrobial activity. Microtiter plate dilution assay (Baindara etal., 2013) was done to study the MIC. MIC values were determined where no visible growth was observed. All independent experiments were repeated four times.

\section{RESULTS AND DISCUSSION \\ CHARACTERIZATION OF BACTERIAL STRAIN}

Based upon colony morphology and upon zone of clearance we have selected a strain designated as SM1 in our study (data not shown). The prime focus of our study was to assess the molecular basis of its antimicrobial activity. In this course we have tried to identify the strain by phenotypic characteristics. Phenotypic and biochemical results revealed that the strain SM1 was a 
Gram-positive, rod shaped bacteria. It showed positive reaction for catalase activity and negative for oxidase activity and produced amylase. BLAST analysis of 16S rRNA gene sequence revealed significant identity $(99.8 \%)$ with $B$. subtilis subsp. In aquosorum, a strain shown to produce fengycin-like lipopeptide. Neighbor joining phylogenetic tree which was constructed with 16S rRNA gene sequences of other members of the genus Bacillus gives confirmation of the strain B. thuringiensis. Result showed that a distinct cluster along with $B$. thuringiensis (Figure 1) is formed with a significant bootstrap value.

\section{PRODUCTION, PURIFICATION AND CHARACTERIZATION OF ANTIMICROBIAL PEPTIDE}

Antimicrobial peptides were produced in conical flask for large scale preparation. The methanol extracts of lipopeptides obtained from the strain was screened for antifungal activity against C. albicans (data not shown) and subsequently purified using RPHPLC. Methanol extract of sample showed multiple peaks during their HPLC analysis. Individual peaks fraction were collected and screened. Fraction 2 showed the highest antifungal activity. The fraction was further purified by a combination of chromatography techniques. The peptide obtained by affinity chromatography was purified by RP-HPLC (Figure 2A) and used to determine molecular mass by MALDI-TOF analysis. The peptide showed molecular mass of 1,492.84 (Figure 2B). The GC-MS analysis revealed the $\beta$-hydroxy fatty acid chain as C-18 long. Recently, Pathak et al. (2012) described details a series of fengycins from Bacillus species and also mentioned the production of new fengycin with molecular mass of 1492.8. The obtained fengycin (1492.84 Da) from SM1 strain is exactly identical with earlier reported fengycin from $B$. subtilis strain $\mathrm{K} 1$, as the amino acid composition of EOrnYTEVPEYV (Pathak et al., 2012).

\section{FORMATION OF SELF-ASSEMBLED STRUCTURE}

Fengycin $\left(0.1 \mathrm{mg} \mathrm{ml}^{-1}\right.$ at neutral $\left.\mathrm{pH}\right)$ was dissolved in chloroform and was rotated at $1000 \mathrm{rpm}$ for $12 \mathrm{~h}$ to form their self-assembled structure using hydrophobic interaction. The circular dichroism spectroscopy, Fourier transform infrared spectroscopy, scanning electron microscopic techniques were used to characterize the selfassembled structure of fengycin. The antifungal and antibacterial activity of the self-assembled structure along with the purified one was assessed.

\section{CIRCULAR DICHROISM ANALYSIS}

Circular dichroism is a sensitive method to the stereoisometry of amino acids constituting the peptide backbone. However, CD results of fengycin are useful, but they are not sufficient to draw a definitive conclusion about the conformation. As expected, this spectrum does not correspond to the conventional spectra of peptides which usually adopt $\alpha$-helical or $\beta$-sheet conformation due to the cyclic structure of lipopeptide hindering that kind of conformation. This spectrum shows the broad positive band with peaks at the region of 218-227 $\mathrm{nm}$ and negative band centered at 205$211 \mathrm{~nm}$ (Figure 3A). It is expected that fengycin contains turns due to its closure ring structures of amino acids precluding the $\beta$-sheet or $\alpha$-helical conformations. The presence of the positive band at 218 and $222 \mathrm{~nm}$ could be explained by the $n-\pi^{*}$ transition occurred within D-amino acids (Vass et al., 2001). Moreover, this band might also be due to an unconventional turn conformation adopted by the peptide cycle of fengycin (Vass et al., 1998, 2001,

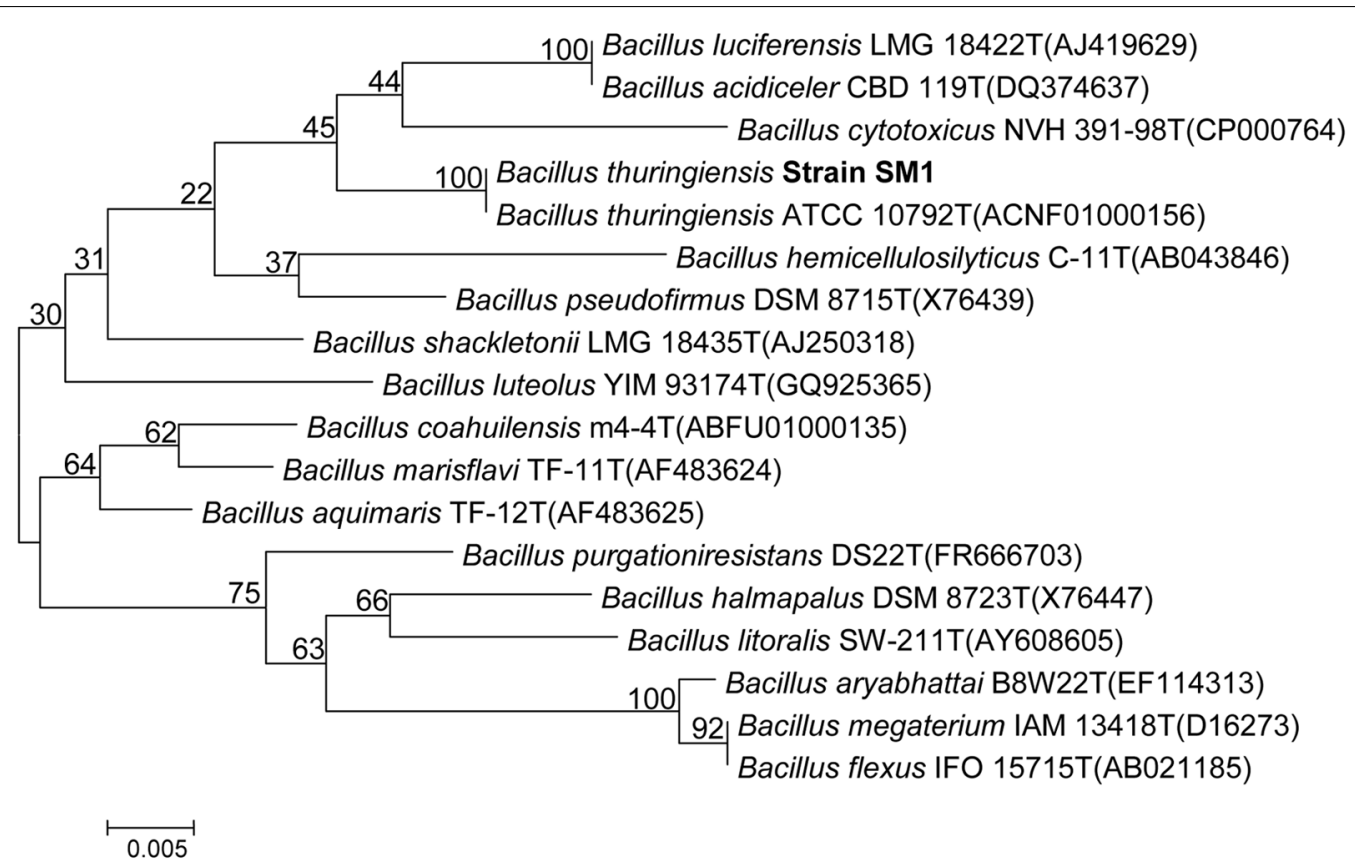

FIGURE 1 | Neighbor-joining phylogenetic tree based on 16S rRNA gene sequences, showing the phylogenetic relationship between Bacillus thuringiensis strain SM1 and other members of the genus Bacillus. Bootstrap values (\%) are given at the nodes. 


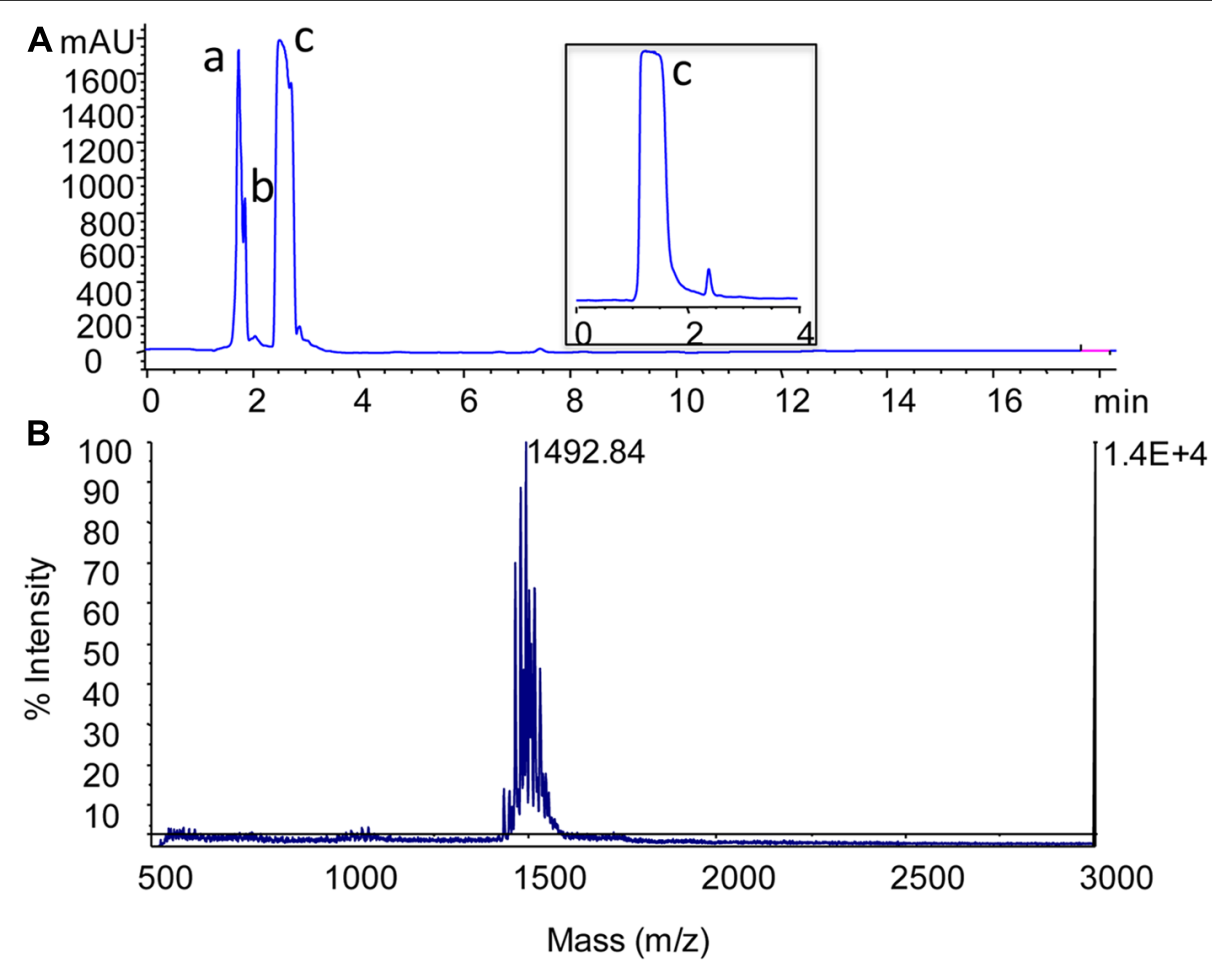

FIGURE 2 | Separation of the antimicrobial lipopeptide from acidic methanol extract by using reversed-phase HPLC. Chromatogram profile of acidic methanol extract showed three peaks ( $a, b$, and $c$ ) and among these fractions, fraction c (lipopeptide) showed antimicrobial activity (A). MALDI-TOF mass spectrum of fengycin-like peptide (B). Spectrum was acquired in positive ion linear mode and reproducibility of the spectrum checked several times with different spots of same sample.
2003, 2010). Another characteristic of the fengycin CD spectrum is the presence of negative bands at 206 and $211 \mathrm{~nm}$, might be corresponding to the $\pi-\pi^{*}$ transition occurring within peptide bonds and is compatible with the presence of $\beta$ sheet conformations. There are no significant positive band shifting at $222 \mathrm{~nm}$ in self-assembled fengycin which suggest the turn conformation present in self-assembled cyclic peptide. Another negative band at the region at 194-206 nm shows major shift in self assemble formation may be indicates the formation of " $\beta$ sheet like micelles" in the structure (Vass et al., 2001).

\section{FTIR-ANALYSIS}

Infrared spectrum of the revealed a broad stretching peak at $3441 \mathrm{~cm}^{-1}$, characteristic of peptides and at $3157.22 \mathrm{~cm}^{-1}$ reflects hydroxyl and amine groups (Figure 3B). Absorption around $2955 \mathrm{~cm}^{-1}$ is assigned to the symmetric stretch $(-\mathrm{C}-\mathrm{H})$ of $\mathrm{CH}_{2}$ and $\mathrm{CH}_{3}$ groups of aliphatic chains. Moreover, an absorption band at $1660 \mathrm{~cm}^{-1}$ depicted stretching mode of the $\mathrm{CO}-\mathrm{N}$ bond and an intense stretching peak around $1470 \mathrm{~cm}^{-1}$ indicated the presence of ester carbonyl groups $(\mathrm{C}=\mathrm{O}$ in $\mathrm{COOH})$ in peptide (Figure 3B). The ester carbonyl group was proved from the band at $1266.23 \mathrm{~cm}^{-1}$ which corresponds to C-O deformation vibrations. Absorption around $1402 \mathrm{~cm}^{-1}$ was also characterized as aromatic group. The amide peak at $1660 \mathrm{~cm}^{-1}$ is shifted to $1642 \mathrm{~cm}^{-1}$ which suggest the aggregation of lipopeptide by the hydrogen bonding in between amide group.
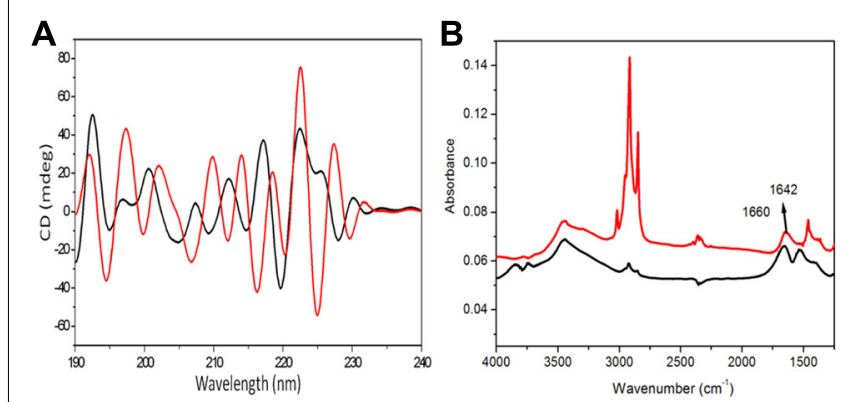

FIGURE 3 | Analytical confirmation of self-assembled structured of fengycin. The deconvoluted CD spectra of the fengycin-like peptides rendering self-assembled cyclic conformation $(\mathbf{A})$; the black and red line represents pure fengycin-like peptide and their self assembled structure, respectively. FTIR spectra of fengycin (B), for both cases the line graph indicates only pure fengycin (black line), fengycin after $12 \mathrm{~h}$ rotation (red line).

\section{SEM IMAGE AND ANTIMICROBIAL ACTIVITY}

Self-assembled fengycin offered a globular micelle structure (Figure 4A). This self-assembled peptide showed same antifungal activity (MIC-15.62 $\mu \mathrm{g} \mathrm{ml}^{-1}$ ) against $A$. niger compared with pure fengycin, whereas, activity was increased one fold when tested against $C$. albicans Table 1. Like most the natural AMPs, fengycin seems to act by making the plasma membrane of the target cell 

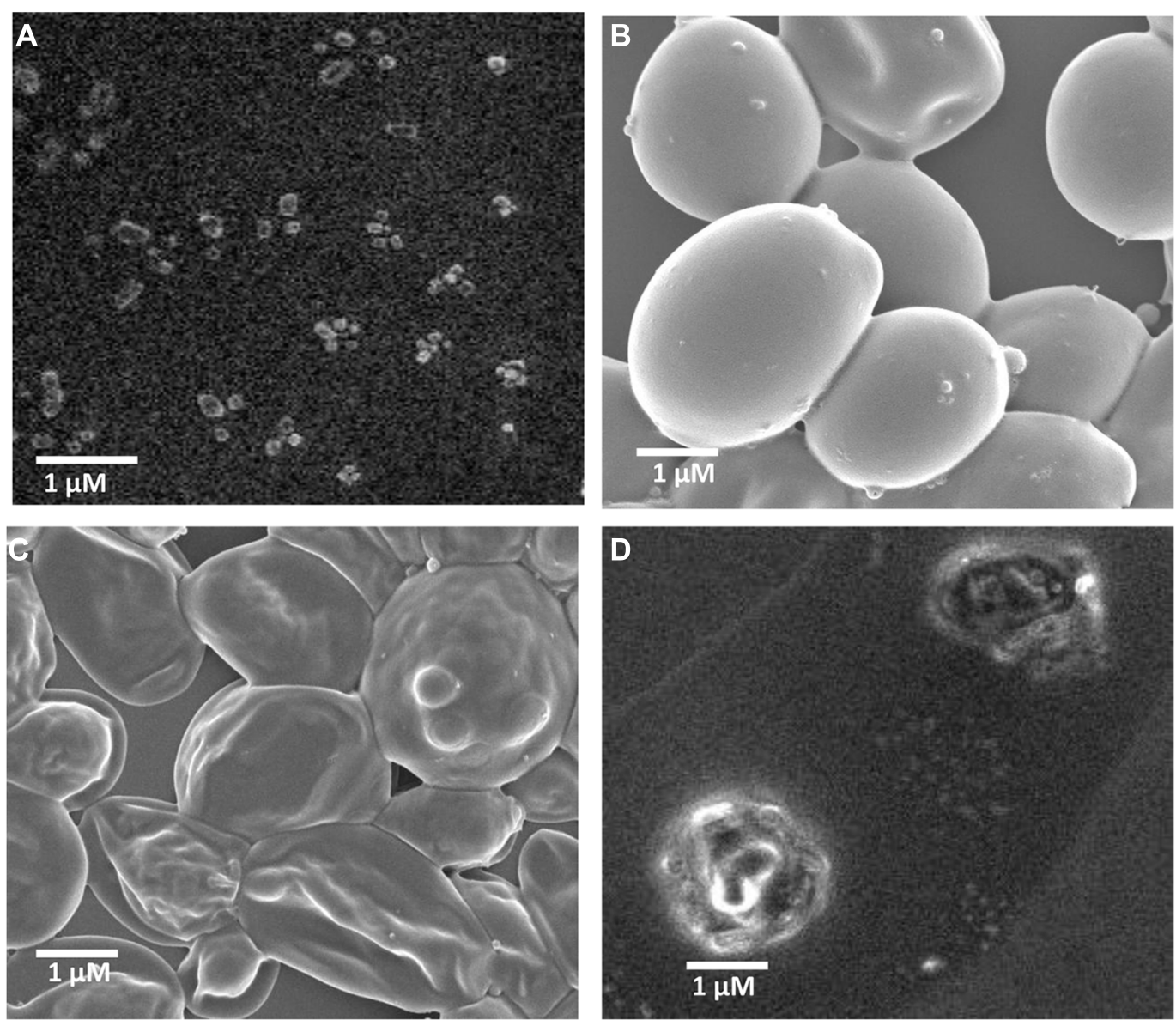

FIGURE 4 | Scanning electron micrograph of fengycin and activity against $\boldsymbol{C}$. albicans cells. Self -assembled globular micelle structure of fengycin (A), scanning electron micrograph of $C$. albicans cells without treatment of fengycin peptide (B), scanning electron micrograph of $C$. albicans cells after treatment of fengycin peptide (C), scanning electron micrograph of C. albicans cells after treatment of self-assembled fengycin peptide (D) more permeable. Fengycin offers a concentration-dependent perturbing effect on the structural and morphological characteristics of DPPC monolayers (Deleu et al., 2005). Antifungal mechanism of fengycin appears to be driven mainly by the physicochemical properties of lipopeptide, i.e., its amphiphilic character and affinity for lipid bilayers (Deleu et al., 2008). To confirm the action on membranolytic or not, SEM images were taken from C. albicans cells with and without treatment of drug molecules. Figure 4B clearly shows that the surface of control group (without fengycin treatment) of fungus was smooth in texture whereas the morphology of the treated cells (Figures 4C,D) displayed

Table 1 | Antimicrobial activity of both pure and self-assembled fengycin.

\section{Compounds}

$\operatorname{MIC}\left(\mu \mathrm{g} \mathrm{ml}^{-1}\right)$

C. Albicans. A. niger S. epidermidis E. coli

$\begin{array}{lllll}\text { Self-assembled fengycin } & 7.81 & 15.62 & 125 & 125 \\ \text { Fengycin } & 15.62 & 15.62 & 1000 & 1000\end{array}$

significant perturbations, rough with number of blebs. Bleb formation following fengycin treatment suggested breakage in the contact between cell wall and membrane. It is quite interesting that self-assembled fengycin affected worst to the fungal strain (Figure 4D). This might be due to change in amphiphilic character and affinity of the self-assembled molecule. The amphiphilic character and affinity can change via self-assembled interaction (Hüttl et al., 2013). Beside one another interesting finding needs attention of further study. Generally fengycin molecule did not show any significant anti bacterial effect. But after self-assembly, it offered a minimum inhibition concentration of $500 \mu \mathrm{g} \mathrm{ml}^{-1}$ against both Gram-positive S. epidermidis and gram negative E. coli. This might be also due to shift of amphiphilic character and affinity resulting action against Gram-positive S. epidermidis.

In conclusion, many Gram-positive bacteria including Bacillus produce AMPs as defense molecule (Baindara et al., 2013). Here we are reporting a fengycin producing strain B. thuringiensis, isolated from soil sample. The strain showed highest similarity with $B$. thuringiensis strains related with fengycin isolation as B. thuringiensis CMB26 and BS8. The molecular mass of the lipopeptide is 1,493.84 suggested it is to be 
fengycin-like peptide. The isolated peptide was subjected to selfassembly. This strategy yields modified fengycin molecule which is active against bacteria. In summary self-assembled fengycin may be a successful antimicrobial compound modifying its action from confined antifungal function. Besides it can open up a new area of research in supramolecular lipopeptide based compound making. This can revealed the mode of action of this unique self-assembled structure to fully evaluate its potential for use as an antimicrobial drug to control the emergence of bacterial infection.

\section{REFERENCES}

Anantharaman, A., Rizvi, M. S., and Sahal, D. (2010). Synergy with rifampin and kanamycin enhances potency, kill kinetics, and selectively of de novodesigned antimicrobial peptides. Antimicrob. Agents Chemother. 54, 1693e1699. doi: 10.1128/AAC.01231-09

Baindara, P., Mandal, S. M., Chawla, N., Singh, P. K., Pinnaka, A. K., and Korpole, S. (2013). Characterization of two antimicrobial peptides produced by a halotolerant Bacillus subtilis strain SK.DU.4 isolated from a rhizosphere soil sample. $A M B$ Express 5, 32. doi: 10.1186/2191-0855-3-2

Deleu, M., Paquot, M., and Nylander, T. (2005). Fengycin interaction with lipid monolayers at the air-aqueous interface - implications for the effect of fengycin on biological membranes. J. Colloid Interface Sci. 283, 358-365. doi: 10.1016/j.jcis.2004.09.036

Deleu, M., Paquot, M., and Nylander, T. (2008). Effect of fengycin, a lipopeptide produced by Bacillus subtilis, on model biomembranes. Biophys. J. 94, 2667-2679. doi: 10.1529/biophysj.107.114090

Fernandez-Lopez, S., Kim, H. S., Choi, E. C., Delgado, M., Granja, J. R., Khasanov, A., et al. (2001). Antibacterial agents based on the cyclic D,L - $\alpha$-peptide architecture. Nature 412, 452-455. doi: 10.1038/35086601

Gilsdorf, J. R., and Zilinskas, R. A. (2005). New considerations in infectious disease outbreaks: The threat of genetically modified microbes. Clin. Infect. Dis. 40, 1160-1165. doi: 10.1086/428843

Hall, T. A. (1999). BioEdit: a user-friendly biological sequence alignment editor and analysis program for Windows 95/98/NT. Nucleic Acids Symp. Ser. 41, 95-98.

Hathout, Y., Ho, Y. P., Ryzhov, V., Demirev, P., and Fenselau, C. (2000). Kurstakins a new class of lipopeptides isolated from Bacillus thuringiensis. J. Nat. Prod. 63, 1492-1496. doi: 10.1021/np000169q

Hbid, C. (1996). Contribution à l'étude de la Relation Entre la Structure des Lipopeptides de B. subtilis et leurs Activités Hémolytique et Antifongique. Ph.D. thesis, Université de Liège, Belgium.

Hüttl, C., Hettrich, C., Miller, R., Paulke, B. R., Henklein, P., Rawel, H., et al. (2013). Self-assembled peptide amphiphiles function as multivalent binder with increased hemagglutinin affinity BMC Biotechnol. 13:51. doi: 10.1186/1472-6750-13-51

Jones, K. E., Patel, N. J., Levy, M. A., Storeygard, A., Balk, D., Gittleman, J. L., et al. (2008). Global trends in emerging infectious diseases. Nature 451, 990-993. doi: 10.1038 /nature06536

Kimura, M. (1980). A simple method for estimating evolutionary rates of base substitutions through comparative studies of nucleotide sequences. J. Mol. Evol. 16, 111-120. doi: 10.1007/BF01731581

Korpole, S., Mayilraj, S., and Chakrabarti, T. (2006). Effluviibacter roseus gen. nov. sp. nov., isolated from muddy water, belonging to the family "Flexibacteraceae". Int. J. Syst. Evol. Microbiol. 56, 1703-1707. doi: 10.1099/ijs.0.64144-0

Loeffler, W., Tschen, J. S. M., Vanittanakom, N., Kugler, M., Knorpp, E., Hsieh, T. F., et al. (1986). Antifungal effects of bacilysin and fengymycin from Bacillus subtilis F-29-3 a comparsion with activities of other Bacillus antibiotics. J. Phytopathol. 115, 204-213. doi: 10.1111/j.1439-0434.1986.tb00878.x

Mandal, S. M., Sharma, S., Pinnaka, A. K., Kumari, A., and Suresh, K. (2013). Isolation and characterization of diverse antimicrobial lipopeptides produced by citrobacter and enterobacter. BMC Microbiol. 13:152. doi:10.1186/1471-2180 13-152

Pathak, K. V., Keharia, H., Gupta, K., Thakur, S. S., and Balaram, P. (2012). Lipopeptides from the banyan endophyte, Bacillus subtilis K1: mass spectrometric characterization of a library of fengycins. J. Am. Soc. Mass. Spectrom. 1716-1728. doi: 10.1007/s13361-012-0437-4

Roy, A., Franco, O. L., and Mandal, S. M. (2013). Biomedical exploitation of self assembled peptide based nanostructures. Curr. Protein Pept. Sci. 14, 07.

Samanta, T., Roymahapatra, G., Porto, W. F., Seth, S., Ghorai, S., Saha, S., et al. (2013). N, N'-olefin functionalized bis-imidazolium gold(I) salt is an efficient candidate to control keratitis-associated eye infection. PLoS ONE 8:e58346. doi:10.1371/journal.pone.0058346

Schneider, J., Taraz, K., Budzikiewicz, H., Deleu, M., Thonart, P., and Jacques, P. Z. (1999). The structure of two fengycins from Bacillus subtilis S499. Z. Naturforsch. C 54, 859-865.

Steller, S., and Vater, J. (2000). Purification of the fengycin synthetase multienzyme system from Bacillus subtilis b213. J. Chromatogr. B Biomed. Sci. Appl. 737, 267275. doi: 10.1016/S0378-4347(99)00481-8

Tamura, K., Peterson, D., Peterson, N., Stecher, G., Nei, M., and Kumar, S. (2011). MEGA5: molecular evolutionary genetics analysis using maximum likelihood, evolutionary distance and maximum parsimony methods. Mol. Biol. Evol. 28, 2731-2739. doi: 10.1093/molbev/msr121

Vanittanakom, N., Loeffler, W., Koch, U., and Jung, G. (1986). Fengycin - a novel antifungal lipopeptide antibiotic produced by Bacillus subtilis F-29-3. J. Antibiot. (Tokyo) 39, 888-901 doi: 10.7164/antibiotics.39.888

Vass, E., Besson, F., Majer, Z., Volpon, L., and Hollosi, M. (2001). Ca(2+)-induced changes of surfactin conformation: a FTIR and circular dichroism study. Biochem. Biophy. Res. Commun. 282, 361-367. doi: 10.1006/bbrc.2001.4469

Vass, E., Hollosi, M., Besson, F., and Buchet, R. (2003). Vibrational spectroscopic detection of beta- and gamma-turns in synthetic and natural peptides and proteins. Chem. Rev. 103, 1917-1954. doi: 10.1021/cr000100n

Vass, E., Kurz, M., Konat, R. K., and Hollosi, M. (1998). FTIR and CD spectroscopic studies on cyclic penta- and hexa-peptides. Detailed examination of hydrogen bonding in b- and c-turns determined by NMR. Spectrochim. Acta A 54, 773-786. doi: 10.1016/S1386-1425(98)00028-6

Vass, E., Majer, Z., Kohalmy, K., and Hollosi, M. (2010). Vibrational and chiroptical spectroscopic characterization of gamma-turn model cyclic tetrapeptides containing two beta-Ala residues. Chirality 22, 762-771. doi: 10.1002/chir.20831

Vater, J., Kablitz, B., Wilde, C., Franke, P., Mehta, N., and Cameotra, S. S. (2002). Matrix-assisted laser desorbtion ionization-time of flight mass spectrometry of lipopeptide biosurfactants in whole cells and culture filtrates of Bacillus subtilis C-1 isolated from petroleum sludge. Appl. Environ. Microbiol. 68, 6210-6219. doi: 10.1128/AEM.68.12.6210-6219.2002

Conflict of Interest Statement: The authors declare that the research was conducted in the absence of any commercial or financial relationships that could be construed as a potential conflict of interest.

Received: 30 August 2013; accepted: 20 October 2013; published online: 21 November 2013.

Citation: Roy A, Mahata D, Paul D, Korpole S, Franco OL and Mandal SM (2013) Purification, biochemical characterization and self-assembled structure of a fengycinlike antifungal peptide from Bacillus thuringiensis strain SM1. Front. Microbiol. 4:332. doi: 10.3389/fmicb.2013.00332

This article was submitted to Antimicrobials, Resistance and Chemotherapy, a section of the journal Frontiers in Microbiology.

Copyright (c) 2013 Roy, Mahata, Paul, Korpole, Franco and Mandal. This is an openaccess article distributed under the terms of the Creative Commons Attribution License (CC BY). The use, distribution or reproduction in other forums is permitted, provided the original author(s) or licensor are credited and that the original publication in this journal is cited, in accordance with accepted academic practice. No use, distribution or reproduction is permitted which does not comply with these terms. 